\title{
Stories from Frequent Attenders: A Qualitative Study in Primary Care
}

\author{
Paula Hodgson, PbD, BSc (Hons) ${ }^{1}$ \\ Patricia Smith, MSc, MRCGP $P^{2}$ \\ Trish Brown, LMSSA, MBBS ${ }^{3}$ \\ Christopher Dowrick, MD, FRCGP \\ 'University Liverpool, Merseyside, UK \\ ${ }^{2}$ The Elms Medical Centre, Liverpool, UK \\ ${ }^{3}$ Fazakerley Hospital, Liverpool, UK
}

\begin{abstract}
PURPOSE Patients who make frequent office visits (frequent attenders) in primary care are often considered a major burden on resources, yet we know little about their perceptions and expectations. We wanted to explore how these patients viewed their rates of consultation, what they expected from the consultation, and how they perceived their relationship with the primary health care team.

METHODS Using a qualitative study design, we undertook in-depth semi-structured interviews with frequent attenders at 4 primary care practices of the Mersey Primary Care RED Consortium in the North West of England. Participants were identified on the basis of office visits at least twice the mean standardized rate for 1 year and a medical assessment that these visits had no important clinical outcome. Interviews with 30 patients aged 24 to 81 years (18 men) were audiotaped and transcribed, and the text was methodically coded; data were analyzed by generating common themes.
\end{abstract}

RESULTS Participants were unable or unwilling to quantify their consultation rates. Despite the assertion by many participants that family doctors are caring, authority figures, there was an underlying tension between such perceptions and the apparent medical mismanagement of symptoms. Their expectations of the consultation were complex and included the presentation of old and new symptoms implicitly embedded within an illness framework. Gaining access to family doctors was generally perceived as problematic.

CONCLUSION The criteria held by family doctors and researchers regarding the appropriate rate of consultations in primary care may not be shared by patients who attend frequently. Such patients require family doctors to acknowledge their symptoms and to provide reassurance

Ann Fam Med 2005;3:318-323. DOI: 10.1370/afm.311.

\section{INTRODUCTION}

7 he term frequent attenders has 2 components within a medical arena. Its overt meaning is numeric or statistical, referring to patients defined simply by their number or rate of physician consultations. ${ }^{1-9}$ It also has a covert, pejorative meaning, referring to those patients who are perceived by family doctors as taking up a disproportionate amount of consultation time ${ }^{10}$ and being a burden on resources and workload. ${ }^{11}$ Proportionally this group appears to be on the increase. ${ }^{12}$ In the current climate of increasing use of primary care services alongside constraints upon the time allowed for a consultation, patients who attend frequently are often a source of frustration to primary care clinicians. ${ }^{13,14}$

Researchers have adopted particular theories and methods ${ }^{15}$ that tend to disseminate a derogatory image of patients who attend frequently. For example, they are reported to be more likely to suffer with psychological and psychiatric problems, such as somatization, to have higher rates of physical disease, and to have poorer health beliefs when compared with those who are not frequent attenders. ${ }^{16-20}$ Despite their heterogeneity, 
there have been attempts to identify subgroups, such as Katon's "distressed high utilizers,"16 and Karlsson's 5 patient groups: patients with entirely physical illness, patients with clear psychiatric illnesses, crisis patients, chronically somatizing patients, and patients with multiple problems. ${ }^{21}$

We decided to approach frequent attendance from another perspective, that is, what do patients themselves think about consulting a family doctor? Are they aware that their consulting rates and their constellation of symptoms are causing problems? Our research questions were influenced by work within the sociology of health and illness that has explored individuals' perceptions and knowledge, ${ }^{22-24}$ and science and technology studies, ${ }^{* 25,26}$ in which the taken-for-granted nature of medical knowledge and its application in practice has been questioned.

We know that consultation decisions by patients who attend frequently are complex, including perceptions of the medical role and past experiences of symptoms. ${ }^{27}$ Although these patients may have an accurate recall of the number of consultations, ${ }^{28}$ they may believe their rates to be average or below average. ${ }^{9}$ Yet the medical community knows little about how these patients view the quality and importance of their interactions with primary health care apart from the suggestion that they may also find these encounters frustrating. ${ }^{29}$ Further exploration of the reasons for consulting frequently may provide insights into the expectations of this group of patients, enabling clinicians to develop more appropriate management strategies.

Our study was designed to answer 3 questions: (1) What are the perceptions of people who attend frequently of their rate of consultation? (2) What do they expect of the consultation? (3) How do they view their relationship with primary health care teams?

\section{METHODS}

Three family doctors and a social scientist developed and undertook the study. The doctors were members of the Mersey Primary Care R\&D Consortium ${ }^{\dagger}$ (the Consortium) and had a particular interest in patients who attend frequently. ${ }^{30-32}$

This study took place in 4 general practices within the Consortium, in the North West of England. Three practices were urban, and 1 was rural. One of the urban practices was single-handed. ${ }^{\ddagger}$ Ethical approval for this study was given by Local Research Ethics Committees.

To encompass numeric and normative components of frequent attendance, we used a 2-stage approach to identify study participants. First we generated lists of patients whose consultations rates were at least twice the mean annual rate for each practice, stratified by sex and 4 age ranges. ${ }^{30}$ Then we identified those patients whose attendance was likely to be problematic for their family doctors by sending each doctor a letter outlining the research and asking them to assign each listed patient to 1 of 3 categories: "'significant clinical outcome"; "no significant clinical outcome"; and "other." We used this process to exclude patients who were consulting frequently for clearly recognized medical problems ("significant clinical outcome") or time-specific events ("other"). Those patients who were judged by a family doctor to have "no significant clinical outcome" were classed as patients who, for the purposes of this study, attend frequently. We contacted them by letter, inviting them to take part in an interview, and enclosed an information sheet and a consent form. Patients who consented were contacted by telephone to arrange a convenient time and location for interview. The lead author carried out semi-structured interviews with these patients during 2001 and 2002.

\section{Analysis}

The interview schedule can be found in the Supplemental Appendix, available online only at http://www. annfammed.org/cgi/content/full/3/4/318/DC1. Interviews were audiotaped and transcribed. Analysis was undertaken using NVIVO. All of the transcripts were open coded by the lead author, and 10 transcripts were open coded by a member of the team who was a qualitative researcher. The next stage of analysis involved generating themes that emerged from the interviews through a review of the open codes. The themes that emerged for the purposes of this report included frequency of consulting, reasons for consulting, bodily perceptions and reassurance, dissatisfaction with consultations, and overcoming obstacles. All of the interviews were included in the analysis; there were no disconfirming cases.

\section{RESULTS}

There were 496 patients who met the initial inclusion criteria by consulting at least as twice as often as the mean, by age and sex, for their practice. Of these, 75 (15\%) were judged by their family doctors to have

\footnotetext{
* Science and technology studies have developed from work within medical sociology and the sociology of scientific knowledge. More recently, there have been moves to work in medicine that have examined the complex interplay between actors, medical knowledge, and medical practices. ${ }^{25}$

† The Mersey Primary Care Research and Development Consortium is made up of 5 primary care practices. The aim of the Consortium is to develop a research culture within primary care and is funded by the Department of Health.

‡ The use of the term single-handed in the UK refers to a primary care practice that is run by 1 family doctor
} 
achieved "no significant clinical outcome" and were therefore classified as patients who, for the purposes of this study, were frequent attenders. All of these patients were contacted, and $30(40 \%)$ agreed to participate in an interview. The 45 patients who were not interviewed fell into several categories: 5 were not living at the last known address; 2 did not have a telephone; 7 agreed to be interviewed but were subsequently unavailable when at the agreed time and location; 16 declined to be interviewed.

Eighteen $(60 \%)$ participants were men and 12 (40\%) were women. Their mean age was 54 years (range 24 to 81 years). Their mean number of consultations was 28 (range 15 to 60) during the previous year.

\section{Frequency of Consulting}

There were 2 types of frequent attenders in this sample. Most participants (27 of 30,90\%) were unable to give a clear indication of their frequency of consultations. Typical responses to the question on the frequency of consultations included the following:

"Don't really know, depends what's wrong with me." (Interview 09)

"Went to the doctor's last week." (Interview 22)

"Must be a couple of weeks ago now." (Interview 13)

"Quite a lot." (Interview 02)

"I've got to go up to the hospital on ... think it's Friday, to see the doctor about my pains." (Interview 10)

"Well, it's just round the corner, only 5 minutes away ... if it's nice I walk round, if it's bad, you know raining, I go in the car." (Interview 14)

"Not sure really, can't really say, hard to remember how much ... not something I keep in my head." (Interview 21)

The second group were crisis patients, with a clear stressor that precipitated high rates of consultation for a specific period. ${ }^{20}$ Three respondents reflected on their high rates of consultation and offered explanations, for example:

"I was going through a really bad patch ... went to see Dr A, and he was really good." (Interview 04)

"Had lots of problems last year and couldn't cope." (Interview 18)

Implicit here is the notion that, for these patients, there were particular times when they were undergoing specific life problems (work-related stress and marital problems) and reported that their family doctors provided considerable support during these times. The separation between acute periods, when they were experiencing life problems, and other times, when they did not need such support from their family doctor, is illustrated by the following response

"Normally twice a year and that would be it." (Interview 11)

\section{Reasons for Consulting}

Reasons for consulting a family doctor were based on representations of family doctors as respected authority figures who are the most appropriate to consult for the distinctive and extensive physical sensations or symptoms that patients perceived to require medical care and reassurance.

Representations of family doctors as having high esteem and status is illustrated by the following quotes:

"They're like your mother and father, you can tell them anything." (Interview 01)

"I suppose they're similar to a priest, somebody you can trust." (Interview 14)

"I don't know ... they know lots, don't they?" (Interview 05)

"They've had all that training and that, they have those books they look things up in." (Interview 12)

"I tell my doctor things I wouldn't say to anybody else, not even the wife. You know when you tell them something, it's between you and him, you know it's not going to get out." (Interview 24)

The belief that a family doctor was the most appropriate and obvious person to manage and treat their symptoms is illustrated below:

"Doctor can sort it out." (Interview 03)

"Well, that's where you go when there's something wrong with you, isn't it?" (Interview 25)

"They know what they're doing, don't they? They know what to get for you, you know, the right drugs and that." (Interview 20)

"They're the ones who tell you what's wrong, they work it out." (Interview 10)

The ability of family doctors to be a part of an individual's unique suffering was expressed by 1 interviewee for whom there was overlap between experiencing prolonged caring (and eventual bereavement for a close family member) and increased contact with his family doctor:

"It was all so difficult when John got ill. We couldn't get any answers from all those doctors, they couldn't do anything, and to make things even worse, I started to get ill, had to give up work ... been there for 23 years. I was trying to cope with his [son's] terrible suffering, and the wife was going out of her mind, knowing he could die at any time. And at the same time ... he was so young, and we thought at first he'd be cured ... it just got worse and worse. When he died, our lives fell apart. There was nothing ... and those doctor's, they don't help me, I've been everywhere ... I'm still waiting for test results." (Interview 26)

The interrelationship between periods of extreme stress and illness are evident in this passage, along with a sense of disappointment in the ability of clinician to prevent this child's death. Furthermore, the extreme- 
and for this interviewee unique-circumstances of his suffering were perceived to be unnoticed by clinicians.

\section{Bodily Perceptions and Reassurance}

Some patients described experiencing a relatively high number of physical sensations that were difficult for them to endure and required reassurance from their family doctor:

"I want to know what's wrong with me, there's always something. Never seem to get clear. Think I'm getting sorted, then something else pops up. Doctor says I've got high blood pressure, you see, and have to be careful. It could be to do with that." (Interview 29)

"Well, like the other morning, I woke up and I had this terrible lump [points to throat]. I couldn't breathe, it was really ... so had to phone the doctors. Couldn't carry on with that, could I? What if I couldn't have breathed? Don't want to wait around with that, do I? Might have ended up in hospital. Then, like another time had this funny breathing, and it just wouldn't stop. I was getting worried so had to go to the doctor's for that." (Interview 01)

"Doctor said, 'Come back if it happens again.' And I'd had another one, felt really bad, didn't know what was going on, just wouldn't go, this funny tingling right the way down here [indicates back of leg], couldn't walk hardly. Then it went here [points to arm], could be something to do with my heart, heard you get funny pains there, you know, before a heart attack." (Interview 15)

"I'd been woken up by it, must've been 2 o'clock. Didn't feel right at all, couldn't get back to sleep, tried everything, thought of calling doctor out to come and see me, but thought, best leave it to morning. And doctor saw me and said I was all right. I was really worried, just couldn't get right in myself. When it's that bad, you have to go see him." (Interview 23)

\section{Dissatisfaction with Consultations}

Despite holding their doctors in high regard, slightly more than 2 thirds of the interviewees $(n=22)$ expressed some form of dissatisfaction with their treatment:

"I told her what was wrong and she said I had, it was to do with my heart. It was my throat that were wrong, so I don't know." (Interview 17)

"I keep telling them, 'What's up? I can't sleep.' They don't seem to be able to do anything, they don't understand." (Interview 21)

"It's a bit annoying, really. I keep saying there's something draining behind my cheek, and then that goes down my throat, some gloopy stuff, but he keeps saying it's something to do with my teeth. I know it's not, it's something behind there. I've been to the dentist, and he can't find anything." (Interview 11)
"I've been a few times to see her, and the last time she said to get on with life, just enjoy it. How can I when I've got this banging going on in my ear? It won't go away by itself, I'm going to have to go back and get it seen to." (Interview 09)

"You see, they can't find out what's wrong with me. They keep saying one thing and giving me these pills. They don't do any good, so I go back, they give me others." (Interview 16)

"She gave me some cream, it didn't do any good, I put it in the bath and had to go back." (Interview 12)

\section{Overcoming Obstacles}

Most interviewees $(n=23)$ reported obstacles to consulting with their family doctor:

"You can never get through, and when you do, they're so rude, you'd think they don't want you, and you can never get the doctor you want ... you have to take next week, but that's no good is it? I want to see Dr B when I'm not well." (Interview 17)

"You have to be up early, get on the phone at quarter past eight and keep ringing 'til you get through." (Interview 13)

"It's a daft system, if you ask me. Used to be all right. Can't see the doctor for 2 weeks-don't have any appointments. I might not be ill then, and the girls say if it's an emergency, then you have to call back, but try getting through-it's always engaged." (Interview 30)

In spite of considerable logistical problems, such as telephone systems and reception staff, there was a sense from the interviews that a consultation with a family doctor would be achieved.

A minority $(n=7)$ reported friendly relationships with reception staff:

"I can go anytime, just phone up and they fit me in. The girls on the telephone know me really well and always sort me out." (Interview 07)

\section{DISCUSSION}

The term frequent attender has particular connotations within a medical-research arena: it generally refers to patients who are considered to be problematic within primary care for the number of times they consult and symptoms that are difficult to manage. A crucial finding from this study was that most of our interviewees were disinclined or unable to quantify their consultations. It may simply be that they were unable to recall the number of visits they made to their family doctor, or there may be a reluctance to disclose rates of consultation, based on an awareness that their visits to their family doctor are frequent and an unwillingness to acknowledge inappropriate behavior. Their rates of consulting might have become naturalized ${ }^{34}$ and so 
not considered to be worth quantifying, that is, visiting the doctor has become commonplace and embedded in their routines. Alternatively, these patients might not perceive their consultations in terms of numbers of visits; they may be visiting their doctor simply as a function of their symptoms, so the number of times they consult is irrelevant. All of these interpretations indicate qualitative differences between the quantification of consultations by family doctors or researchers and patients' perceptions of their attendance rate. We conclude that the norms reported in the literature about consultation rates do not apply to this group of patients.

It is entirely appropriate to consult a family doctor when experiencing physical symptoms that are perceived to be related to some form of illness: $90 \%$ of initial contacts with health professionals are located in primary care. ${ }^{33}$ Family doctors are generally perceived as situated within an illness framework and can diagnose conditions and manage symptoms. The multiplicity of complaints and symptoms reported during our interviews, however, suggests a high degree of medicalization ${ }^{35}$ by patients and family doctors, which is in agreement with the finding that patients who consult frequently have a much higher rate $(40 \%$ to $50 \%)$ of physical disease than does the average attender. ${ }^{17,18}$

The apparent inability of these patients to accommodate physical sensations or symptoms and to consistently seek out medical advice (despite such obstacles as reception staff and practice systems) suggests several possibilities. Their physical feedback mechanisms may be amplified, leading to a heightened experience of their bodies and an inability to distinguish between normal and abnormal sensations. ${ }^{19}$ They lack the ability to reassure themselves that they are not ill or to accommodate bodily changes. There are underlying problems (including mental health and social issues) that are consistently unresolved and are expresed as physical symptoms. ${ }^{2,36}$

Respondents' perception that doctors misunderstood their symptoms led to the associated belief that their doctors were managing their illnesses inappropriately. Such tension can be understood in a number of ways. There may be poor communication between frequent attenders and family doctors that reflects a dysfunctional relationship. ${ }^{31}$ Family doctors may not communicate adequately their diagnosis and management of symptoms, and patients who attend frequently may be selective about the information that they choose to give and to receive. As long as these patients perceive and represent their symptoms and illnesses as managed inappropriately by family doctors, there will always be a justifiable reason to frequently visit their family doctor.

We suggest at least 2 levels of need among patients who attend frequently. First, their apparent high levels of physical symptoms have to be acknowledged by a significant other, such as a family doctor. Second, their symptoms require legitimization by being situated within an illness framework. The dissatisfaction with family doctors expressed by some interviewees, however, indicates a third component to their needs, that is, their particular suffering is considered unique and cannot be fully understood, even by an authority on illness, such as a family doctor.

\section{Strengths and Limitations of the Study}

We used a novel method to determine which patients family doctors consider to frequent attenders. Although, similar to other research, ${ }^{30}$ we used quantitative definitions of frequent attendance to generate lists of patients who had office visits at twice the mean rate for the practice and age ranges, the rating of these lists of patients was undertaken by family doctors for whom "no significant clinical outcome" was used as an identifier for patients who frequently attend. There may have been differences between doctors in their use of the criteria (which would require further refinement), as evidenced by the 3 interviewees in this study who could be considered to be crisis patients rather than frequent attenders. We believe, however, that using family doctors to identify those patients who they consider attend frequently is a useful strategy that can be further developed.

It was difficult to find patients who would agree to an interview for this study. Ethical considerations, however, constrained us from determining whether the potential participants who were not interviewed (60\%) are the more challenging for family doctors in terms of their consultation rates and symptoms.

\section{Implications for Future Research and Clinical Practice}

Clinical management of patients who attend frequently is characterized by mutual frustration and a lack of reciprocity. ${ }^{37}$ Frequent attenders require consistent acknowledgment and legitimization of their perceived unique suffering. An increased awareness by physicians of their patients' perceptions and expectations is essential. Instead of giving patients medications for their symptoms, clinicians might find it more helpful to focus on reassurance techniques using explanations that relate to the patient's conceptual framework and exempt the patient from blame. ${ }^{32}$ To design effective educational interventions, we need future research that examines clinicians' interactions with patients who attend frequently.

To read or post commentaries in response to this article, see it online at http://www.annfammed.org/cgi/content/full/3/4/318. 
Key words: Frequent attendance; primary care; patient perceptions; medically unexplained symptoms (MUS)

Submitted July 26, 2005; submitted, revised, February 2, 2005; accepted February 7, 2005.

\section{References}

1. Bellon JA, Delgado A, Luna JD, Lardelli P. Psychosocial and health belief variables associated with frequent attendance in primary care. Psychol Med. 1999;29:1347-1357.

2. Semmence A. Chronic high users in a general practice. A preliminary study. J R Coll Gen Pract. 1969;17:304-310.

3. Wamosher Z. The returning patient - a survey of patients with a high attendance rate. J R C Gen Pract. 1966;11:166-173.

4. Browne GB, Humphrey B, Pallister R, Browne JA, Shetzer L. Prevalence and characteristics of frequent attenders in a prepaid Canadian family practice. J Fam Pract. 1982;14:63-71

5. Westhead JN. Frequent attenders in general practice: medical, psychological and social characteristics. J R Coll Gen Pract. 1985;35:337-340.

6. Robinson JO, Granfield AJ. The frequent consulter in primary medical care. J Psychosom Res. 1986;30:589-600.

7. Freeborn DK, Pope CR, Mullooly JP, McFarland BH. Consistently high users of medical care among the elderly. Med Care. 1990;28:527-540.

8. Ward AM, Underwood P, Fatovich B, Wood A. Stability of attendance in general practice. Fam Pract. 1994;11:431-437.

9. Heywood PL, Blackie GC, Cameron IH, Dowell AC. An assessment of the attributes of frequent attenders to general practice. Fam Pract. 1998; 15:198-204.

10. Collyer JA. Psychosomatic illness in a solo family practice. Psychosomatics. 1979;20:762-763, 767.

11. Mathers N, Jones N, Hannay D. Heartsink patients: a study of their general practitioners. Br J Gen Pract. 1995;45:293-296.

12. Gill D, Dawes M, Sharpe M, Mayou R. GP frequent consulters: their prevalence, natural history, and contribution to rising workload. $\mathrm{Br} J$ Gen Pract. 1998;48:1856-1857.

13. Mathers NJ, Gask L. Surviving the 'heartsink' experience. Fam Pract. $1995 ; 12: 176-183$.

14. Hartz AJ, Noyes R, Bentler SE, et al. Unexplained symptoms in primary care: perspectives of doctors and patients. Gen Hosp Psychiatry. 2000;22:144-152.

15. Fujimura J. Crafting Science; a Sociohistory of the Quest for the Genetics of Cancer. Cambridge, Mass: Harvard University Press; 1996.

16. Katon W, Von Korff M, Lin E, et al. Distressed high utilizers of medical care. DSM-III-R diagnoses and treatment needs. Gen Hosp Psychiatry. 1990;12:355-362.

17. Portegijs PJ, Jeuken FM, van der Horst FG, Kraan HF, Knottnerus JA. A troubled youth: relations with somatization, depression and anxiety in adulthood. Fam Pract. 1996;13:1-11.
18. Courtenay MJ, Curwen MP, Dawe D, Robinson J, Stern MJ. Frequent attendance in a family practice. J $R$ Coll Gen Pract. 1975;24:251-261.

19. Westhead JN. Frequent attenders in general practice: medical, psychological and social characteristics. J R Coll Gen Pract. 1985;35:337-340.

20. Sensky T, MacLeod AK, Rigby MF. Causal attributions about common somatic sensations among frequent general practice attenders. Psychol Med. 1996;26:641-646.

21. Karlsson H, Joukamaa M, Lahti I, Lehtinen V, Kokki-Saarinen T. Frequent attender profiles: different clinical subgroups among frequent attender patients in primary care. J Psychosom Res. 1997;42:157-166

22. Graham H, Oakley A. Competing ideologies of reproduction: Medical and maternal perspectives on pregnancy. In: Women, Health and Reproduction. Roberts H, ed. London: Routledge and Kegan Paul; 1986.

23. Stacey M. Lay knowledge: a personal view. In: Researching the People's Health. Popay J, Williams GH, eds. London: Routledge; 1994.

24. Busby H, Williams G, Rogers A. Bodies of knowledge: lay and biomedical understandings of musculoskeletal disorders. In: The Sociology of Medical Science and Technology. Elston M, ed. Oxford, UK: Blackwell; 1997.

25. Mol A. Ontological Politics. A word and some questions. In: Actor Net work Theory and After. Law J, Hassard J, eds. Oxford, UK: Blackwell; 1999.

26. Star SL, Greisemer JR. "Institutional ecology" translations and boundary objects: amateurs and professionals in Berkeley's museum of vertebrate zoology. Soc Studies Science. 1989;19:387-420.

27. Neal RD, Heywood PL, Morley S. Frequent attenders' consulting patterns with general practitioners. Br J Gen Pract. 2000;50:972-976.

28. Little P, Somerville J, Williamson I, et al. Psychosocial, lifestyle, and health status variables in predicting high attendance among adults. Br J Gen Pract. 2001;51:987-994.

29. Jackson JL, Kroenke K. Difficult patient encounters in the ambulatory clinic: clinical predictors and outcomes. Arch Intern Med. 1999;159:1069-1075.

30. Dowrick CF, Bellon JA, Gomez MJ. GP frequent attendance in Liverpool and Granada: the impact of depressive symptoms. Br J Gen Pract. 2000;50:361-365.

31. Dowrick CF. Why do the O'Sheas consult so often? An exploration of complex family illness behaviour. Soc Sci Med. 1992;34:491-497.

32. Dowrick CF, Ring A, Humphris GM, Salmon P. Normalisation of unexplained symptoms by general practitioners: a functional typology. Br J Gen Pract. 2004;54:165-170.

33. Parliament, House of Commons, Committee of Public Accounts. Seventeenth Report Health of the Nation: A Progress Report. London: Department of Health; 1997.

34. Schutz A. The stranger: an essay in social psychology. Amer J Sociology. 1944;499-507:499-507.

35. Illich I. Limits to Medicine. London: Marion Boyars; 1976.

36. McArdle C, Alexander WD, Boyle CM. Frequent attenders at a health centre. Practitioner. 1974;213:696-702.

37. Parsons T. The Social System. Glencoe, III: The Free Press; 1951. 